\title{
Paclitaxel injection concentrate for nanodispersion versus $n a b$-paclitaxel in women with metastatic breast cancer: a multicenter, randomized, comparative phase II/III study
}

\author{
Minish M. Jain ${ }^{1}$ - Smita U. Gupte ${ }^{2}$ - Shekhar G. Patil ${ }^{3}$ - Anand B. Pathak ${ }^{4}$. \\ Chetan D. Deshmukh ${ }^{5}$ - Niraj Bhatt ${ }^{6}$. Chiramana Haritha ${ }^{7}$ - K. Govind Babu ${ }^{8}$. \\ Shailesh A. Bondarde ${ }^{9}$ Raghunadharao Digumarti ${ }^{10} \cdot$ Jyoti Bajpai $^{11}$. \\ Ravi Kumar ${ }^{12}$ - Ashish V. Bakshi ${ }^{13}$. Gouri Sankar Bhattacharya ${ }^{14}$. \\ Poonam Patil $^{15}$ • Sundaram Subramanian ${ }^{16}$ - Ashok K. Vaid ${ }^{17}$. Chirag J. Desai ${ }^{18}$. \\ Ajay Khopade $^{19} \cdot$ Geetanjali Chimote $^{19} \cdot$ Poonamalle P. Bapsy $^{19} \cdot$ Shravanti Bhowmik $^{19}$
}

Received: 17 January 2016/ Accepted: 25 February 2016/Published online: 3 March 2016

(C) The Author(s) 2016. This article is published with open access at Springerlink.com

\begin{abstract}
Paclitaxel is widely used in the treatment of patients with metastatic breast cancer (MBC). Formulations of paclitaxel contain surfactants and solvents or albumin derived from human blood. The use of co-solvents such as polyoxyethylated castor oil is thought to contribute to toxicity profile and hypersensitivity reactions as well as leaching of plasticizers from polyvinyl chloride bags and infusion sets. Currently, nab-paclitaxel, an albumin-bound paclitaxel in nanometer range continues to be the preferred taxane formulation used in clinic. This study (CTRI/2010/ 091/001116) investigated the efficacy and tolerability of a polyoxyethylated castor oil- and albumin-free formulation of paclitaxel [paclitaxel injection concentrate for nanodispersion (PICN)] compared with $n a b$-paclitaxel in women
\end{abstract}

Previous presentation Presented in part at the 50th Annual Meeting of the American Society of Clinical Oncology; May 30-June 3, 2014; Chicago, IL

Shravanti Bhowmik

shravanti.bhowmik@sparcmail.com

KEM Hospital and Research Center, Pune, India

Cancer Clinic, Nagpur, India

HCG Bangalore Institute of Oncology, Bengaluru, India

Cancer Care Clinic, Nagpur, India

5 Deenanath Mangeshkar Hospital and Research Centre, Pune, India

6 Kailash Cancer Hospital and Research Centre, Goraj, India

7 MS Patel Cancer Center, Karamsad, India

Kidwai Memorial Institute of Oncology, Bengaluru, India

9 Shatabdi Super Specialty Hospital, Nashik, India

10 Nizam's Institute of Medical Sciences, Hyderabad, India with refractory MBC. The current study was a multicenter, open-label, parallel-group, randomized, comparative phase II/III trial evaluating the efficacy and safety of PICN $\left(260 \mathrm{mg} / \mathrm{m}^{2}[n=64]\right.$ and $295 \mathrm{mg} / \mathrm{m}^{2}[n=58]$ every 3 weeks) compared with $n a b$-paclitaxel $\left(260 \mathrm{mg} / \mathrm{m}^{2}\right.$ every 3 weeks $[n=58])$ in women 18 and 70 years old with confirmed MBC. Overall response rate (ORR) was assessed with imaging every 2 cycles. An independent analysis of radiologic data was performed for evaluable patients. Progression-free survival (PFS) was a secondary efficacy measure. Independent radiologist-assessed ORRs in the evaluable population of women aged $\geq 70$ years were 35 , 49, and $43 \%$ in the PICN $260 \mathrm{mg} / \mathrm{m}^{2}$, PICN $295 \mathrm{mg} / \mathrm{m}^{2}$, and nab-paclitaxel $260 \mathrm{mg} / \mathrm{m}^{2}$ arms, respectively. Median PFS in the evaluable population was 23,35 , and 34 weeks in the PICN $260 \mathrm{mg} / \mathrm{m}^{2}$, PICN $295 \mathrm{mg} / \mathrm{m}^{2}$, and $n a b$-paclitaxel $260 \mathrm{mg} / \mathrm{m}^{2}$ arms, respectively. Adverse events

11 Department of Medical Oncology, Tata Memorial Hospital, Mumbai, India

12 Global Hospital, Hyderabad, India

13 Kaushalya Medical Foundation, Thane, India

14 Orchid Nursing Home, Kolkata, India

15 Specialty Cancer Care Department, Manipal Hospital, Bengaluru, India

16 VS Hospital, Chennai, India

17 Medanta Medicity Hospital, New Delhi, India

18 Hemato-Oncology Clinic, Vedanta Institute of Medical Sciences, Ahmedabad, India

19 Sun Pharma Advanced Research Co. Ltd., 17/B Mahal Industrial Estate, Mahakali Caves Road, Andheri (E), Mumbai 400093, India 
occurred in similar proportions of patients across treatment arms. Hypersensitivity reactions were not frequently observed with the clinical use of PICN across the treatment cohorts. In women with metastatic breast cancer, PICN at 260 and $295 \mathrm{mg} / \mathrm{m}^{2}$ every 3 weeks was effective and well tolerated and showed similar tolerability compared with $n a b$-paclitaxel $260 \mathrm{mg} / \mathrm{m}^{2}$ every 3 weeks. Statistically, significant differences were not observed in the PICN and $n a b$-paclitaxel treatment arms for radiologist-assessed ORR or median PFS. The novel paclitaxel formulation, PICN, offers apart from efficacy, potential safety advantage of decreased use of corticosteroid pretreatment and the absence of the risk of transmission of blood product-borne disease.

Keywords Breast neoplasms · Chemistry ·

Pharmaceutical · Disease-free survival · Paclitaxel

\section{Implications for practice}

The chemotherapeutic agent paclitaxel is widely used in the treatment of women with metastatic breast cancer (MBC). However, currently available formulations contain additives, such as surfactants, solvents that are potentially toxic or lead to hypersensitivity reactions. The current study investigated the efficacy and safety of paclitaxel injection concentrate for nanodispersion (PICN), which is free of these additives, in women with refractory MBC. Based on radiologist-assessed overall response rate and progression-free survival, PICN is as effective and well tolerated as nab-paclitaxel, an albumin-bound paclitaxel in nanometer range which is the current preferred taxane formulation in clinical practice and may have a safety advantage regarding decreased use of pretreatment corticosteroids.

\section{Introduction}

Paclitaxel is a widely used chemotherapeutic agent that plays a pivotal role in the treatment of patients with metastatic breast cancer (MBC) [1]. The first approved formulation (Taxol ${ }^{\circledR}$; Bristol-Myers Squibb, Princeton, NJ) was prepared in nonionic surfactant polyoxyethylated castor oil; (Kolliphor $\mathrm{EL}^{\circledR}$, formerly known as Cremophor ${ }^{\circledR}$ EL, BASF, Ludwigshafen, Germany) and ethanol to enhance drug solubility [2]. The polyoxyethylated castor oil adds to the toxic effects of paclitaxel by producing or contributing to hypersensitivity reactions that commonly occur during infusion, affecting 25-30\% of treated patients $[3,4]$. Routine premedication with $\mathrm{H}_{1}$ blockers and $\mathrm{H}_{2}$ blockers, as well as corticosteroids, has become standard practice to minimize the incidence and severity of these sometimes fatal reactions [5]. In addition, plasticizers from polyvinyl chloride bags and infusion sets may leach as a result of the polyoxyethylated castor oil and ethanol solvent, necessitating preparation and administration of conventional paclitaxel in glass bottles or nonpolyvinyl chloride infusion systems and with in-line filtration [6].

With the advancement of nanotechnology applications in healthcare, newer nanoparticle strategies to address the shortcomings of solvent-based taxanes are under clinical evaluation, the first of which to be marketed is nab-paclitaxel (Abraxane $^{\circledR}$; Celgene Corporation, Summit, NJ). Nab-paclitaxel (an albumin-bound paclitaxel in nanometer range formulation) is approved for the treatment of patients with breast cancer who fail to respond to combination chemotherapy for metastatic disease or experience a relapse within 6 months of adjuvant chemotherapy [7]. Nab-paclitaxel, demonstrated a significant improvement in overall response rate and reduction in toxicities in patients with metastatic breast cancer in a pivotal Phase III clinical trial comparing efficacy of nab-paclitaxel to Taxol in patients with metastatic breast cancer (Study CA012-0) [8]. Routine premedication against hypersensitivity reactions was not required during clinical trials of $n a b$-paclitaxel [9-12] and is not routinely required during its clinical use. Paclitaxel injection concentrate for nanodispersion (PICN; Sun Pharma Advanced Research Co. Ltd., Mumbai, India) is an alternative solvent-free formulation of paclitaxel. PICN is under investigation as a polyoxyethylated castor oil- and albuminfree self-assembly nanoparticle formulation of paclitaxel (100-150 nm) stabilized with a polymer (polyvinylpyrrolidone) and lipid (cholesteryl sulfate and caprylic acid) using Nanotecton ${ }^{\circledR}$ technology (Sun Pharma Advanced Research Co. Ltd.). Unlike, nab-paclitaxel, which utilizes albumin of biological origin, PICN makes use of polymer and lipid mixtures. While nab-paclitaxel continues to be the preferred taxane formulation used in clinic, newer formulations of paclitaxel such as PICN could have potential advantages which need to be evaluated in randomized trials. The current randomized trial aimed to understand the clinical similarities and dissimilarities between PICN and nab-paclitaxel and explore potential advantages offered by PICN due to the differences in the nanotechnology platforms used.

The doses for the current study were derived from the Phase I safety, efficacy, and pharmacokinetic study of Paclitaxel nano-dispersion injection in subjects with metastatic breast cancer. To arrive at a MTD, by adapting the $3+3$ dose escalation design, the planned dose escalations were performed at 260, 295, and $325 \mathrm{mg} / \mathrm{m}^{2}$. At $260 \mathrm{mg} / \mathrm{m}^{2}$ one subject of the nine subjects enrolled had Cycle 1 DLT of grade 4 neutropenia while at the $295 \mathrm{mg} / \mathrm{m}^{2}$ dose, seven subjects were enrolled and treated, and no Cycle 1 DLTs were observed. These dose escalations resulted in an MTD of 
$325 \mathrm{mg} / \mathrm{m} 2$ for PICN. Since, both 260 and $295 \mathrm{mg} / \mathrm{m}^{2}$ doses were observed to be safe in every 3 -week cycle in a limited study population of 16 subjects, they were selected in comparison with nab-paclitaxel for the study [13]. Additionally, the phase I study also demonstrated that PICN administration was free of hypersensitivity reactions despite a lack of premedication. The current comparative phase II/III trial hence was conducted to evaluate the efficacy and safety of 2 dosing regimens of PICN (260 and $295 \mathrm{mg} / \mathrm{m}^{2}$ every 3 weeks) compared with the approved dose of nab-paclitaxel (260 mg/m ${ }^{2}$ every 3 weeks) in women with MBC. Emphasis was also laid on ensuring that the PICN administration was without premedication to demonstrate negligible hypersensitivity risk associated with clinical use of PICN.

As per the emerging literature on taxanes, the optimal way to administer paclitaxel is in weekly setting and not every 3 weeks as demonstrated by clinical trials conducted using solvent-based taxanes such as Taxol [14]. Solventbased paclitaxel is being used in a weekly dosing regimen [15]. However, the prescribing information of nab-paclitaxel does not support the weekly use of nab-paclitaxel. The weekly dose for nab-paclitaxel is under evaluation in several clinical trials [16]. Additionally, when evaluated in a randomized phase III trial of weekly paclitaxel (P) compared to weekly nanoparticle albumin-bound nab-paclitaxel (NP) or ixabepilone (Ix) with or without bevacizumab (B) as first-line therapy for locally recurrent or metastatic breast cancer (MBC), weekly nab-paclitaxel was associated with significantly higher Grade $2+$ sensory neuropathy and Grade $3+$ hematological toxicity (Grade $2+$ sensory neuropathy was $48 \%$ for nab-paclitaxel, $44 \%$ for ixabepilone and $37 \%$ for Paclitaxel; Grade $3+$ hematologic toxicity was $49 \%$ for nab-paclitaxel, $20 \%$ for ixabepilone, and $12 \%$ for paclitaxel and inferior hazard ratio [17]. Currently, there is lack of clinical literature on randomized clinical trial comparing efficacy and safety of weekly nab-paclitaxel with conventional solvent-based formulations of paclitaxel to support a dose and methodology for use of weekly nab-paclitaxel.

Therefore, the currently approved 3-weekly dosing regimen was selected (in this trial).

The weekly dose for PICN has also been determined in phase 1 trials in the US and India and could potentially be selected for further development and randomized clinical studies [18, 19].

\section{Patients and methods}

\section{Patients}

Women between age 18 and 70 years with measurable histologically or cytologically confirmed MBC were eligible to participate in this study if they were candidates for singleagent paclitaxel therapy in accordance with current standards of care. Inclusion criteria were as follows: Eastern Cooperative Oncology Group (ECOG) performance status score $\leq 2$; life expectancy $\geq 12$ weeks; prior use of chemotherapy as adjuvant therapy or for metastatic disease; use of chemotherapy (apart from palliative bisphosphonate therapy), major surgery, or radiotherapy $>4$ weeks before enrollment (6 weeks for mitomycin $\mathrm{C}$ or nitrosoureas) and free of any toxicity incurred as a result of such prior therapy; and prior hormonal therapy to be completed $\geq 2$ weeks before enrollment. Organ and immune function had to be adequate, as indicated by the following laboratory test values obtained $\leq 2$ weeks before dosing: absolute neutrophil count (ANC) $\geq 1500 / \mu \mathrm{L}$, platelet count $\geq 100,000 / \mu \mathrm{L}$, hemoglobin level $\geq 9.0 \mathrm{~g} / \mathrm{dL}$, serum creatinine level $\leq 2.0 \mathrm{mg} / \mathrm{dL}$, total bilirubin level $\leq 1.5 \mathrm{mg} / \mathrm{dL}$ (or $\leq 2.0 \mathrm{mg} / \mathrm{dL}$ for liver metastasis), aspartate aminotransferase and alanine aminotransferase levels $\leq 2.5$ times the upper limit of normal (or $\leq 5$ times for liver metastasis), and alkaline phosphatase level $\leq 5$ times the upper limit of normal (unless bone metastases are present in the absence of liver metastases). Women of childbearing potential were required to have a negative urine pregnancy test result and use an acceptable method of birth control as judged by the investigator from $\geq 2$ weeks before study entry and throughout the study; otherwise, they had to be postmenopausal for $\geq 1$ year or surgically sterile.

Exclusion criteria were as follows: relapse within 48 weeks after completion of adjuvant taxane therapy; any other malignancy in the previous 5 years except for nonmelanoma skin cancer, cervical intraepithelial neoplasia, or in situ cervical cancer; only evidence of metastasis as lytic or blastic bone lesions or pleural effusion or ascites; known hypersensitivity to study drugs or their excipients; treatment with any investigational agent within 30 days of study entry; clinically evident active central nervous system metastases, including leptomeningeal involvement, requiring corticosteroid or radiation therapy; pre-existing peripheral neuropathy grade $\geq 1$; any severe concurrent disease that would make the patient inappropriate for study entry in the judgment of the investigator; prior taxane use for $\mathrm{MBC}$; and the presence of pleural or ascitic fluid (if present, fluid was tapped before dosing).

\section{Study design and treatment}

This was a multicenter, open-label, parallel-group, randomized, comparative phase II/III study. Patients were screened and recruited at 20 sites in India. The study was conducted in compliance with the Declaration of Helsinki and International Conference on Harmonisation Good Clinical Practice Guidelines. All patients provided written informed consent. The protocol and its subsequent 
amendments were approved by the Drugs Controller General of India (DCGI) and the institutional review board at each of the participating centers. The trial was registered on Clinical Trials Registry-India (www.ctri.nic.in) on July 9, 2010, and the WHO Clinical Trial Registry on June 8, 2009 (CTRI number: CTRI/2010/091/001116).

An independent company using personnel otherwise unrelated to this study randomly assigned (using a computer-generated randomization code) patients to one of the following 3 treatment arms (1:1:1 ratio): PICN $260 \mathrm{mg} / \mathrm{m}^{2}$, PICN $295 \mathrm{mg} / \mathrm{m}^{2}$, or $n a b$-paclitaxel $260 \mathrm{mg} / \mathrm{m}^{2}$ over the course of $30 \mathrm{~min}$ on day 1 of each 3 -week cycle. Routine premedication to prevent hypersensitivity reactions with paclitaxel was not required. PICN and $n a b$-paclitaxel concentrates were reconstituted for infusion in $5 \%$ dextrose and $0.9 \%$ saline, respectively. Treatment was continued until disease progression, occurrence of unacceptable toxicity, or withdrawal of patient consent. Patients were also discontinued from the study dependent on investigator discretion, loss to follow-up, noncompliance, death, or complete response.

Dose adjustments for $n a b$-paclitaxel were made in accordance with the authorized package insert. For severe neutropenia (absolute neutrophil count $[\mathrm{ANC}]<500 / \mu \mathrm{L}$ for $\geq 1$ week) or severe sensory neuropathy, the dosage of $n a b$-paclitaxel was reduced to $220 \mathrm{mg} / \mathrm{m}^{2}$ for subsequent courses. For recurrence of severe neutropenia or severe sensory neuropathy, there was an additional dose reduction to $180 \mathrm{mg} / \mathrm{m}^{2}$. For grade 3 sensory neuropathy, treatment was held until resolution to grade 1 or 2 , followed by a dose reduction for all subsequent courses.

For PICN, a maximum of 2 dose reductions were allowed: (1) 295-260 and $220 \mathrm{mg} / \mathrm{m}^{2}$; and (2) 260-220 and $175 \mathrm{mg} / \mathrm{m}^{2}$. The patient was withdrawn from the study if more than 2 dose reductions were required. No action was to be taken for the first incidence of $\mathrm{ANC}<500 / \mu \mathrm{L}$ without fever, but dose reduction was instituted for recurrence or for the first instance of neutropenic fever/sepsis. For subsequent cycles, the dose was maintained if granulocyte colony-stimulating factor was given as secondary prophylaxis or reduced in the absence of growth factor therapy. Dose reduction was required for grade 3/4 thrombocytopenia. Dosing was not resumed until the ANC was $\geq 1500 / \mu \mathrm{L}$ and the platelet count was $\geq 100,000 / \mu \mathrm{L}$. For any nonhematologic toxicity grade $\geq 2$, dose delay was permitted. Dose delay was required for neurotoxicity grade $\geq 2$. For any grade $3 / 4$ nonhematologic toxicity, dose reduction was required. A maximum of 2 dose reductions were permitted. In the event of any other toxicity that was grade $\geq 2$ (excluding alopecia), which in the investigator's opinion was probably or definitely related to PICN, a dose delay was permitted.

\section{Patient evaluation}

Overall response rate (ORR), defined as the percentage of patients who achieved complete or partial response for target and nontarget lesions according to RECIST version 1.1, was determined every 2 cycles after a minimum of 2 cycles of therapy in the intention-to-treat (ITT) population assessed by imaging (computed tomography or magnetic resonance imaging). An independent analysis of radiologic data using RECIST version 1.1 was performed for evaluable patients by a group of radiologists who were blind to treatment and unrelated to the trial. Radiologic data for 136 patients $\left(48,41\right.$, and 47 in the PICN $260-\mathrm{mg} / \mathrm{m}^{2}$, PICN $295-\mathrm{mg} / \mathrm{m}^{2}$, and $n a b$-paclitaxel $260-\mathrm{mg} / \mathrm{m}^{2}$ arms, respectively) underwent independent radiologic assessment. Progression-free survival (PFS) was a secondary efficacy measure.

Safety was assessed by adverse events (AEs) using Common Terminology Criteria for Adverse Events version 4.02. Adverse events were classified with respect to relationship to treatment (unrelated, unlikely, possibly, probably) and intensity, and were derived from changes in vital signs and laboratory parameters, as well as by indirect unbiased questioning, spontaneous patient reports, and observation.

\section{Statistical analysis}

This study was designed to allow for direct comparisons of ORR between the 3 treatment arms. The underlying assumptions for the sample size calculation were based on an ITT population with an ORR of $21.51 \%$ for the $n a b$ paclitaxel group and an ORR of $16.5 \%$ for the PICN group at the end of 6 cycles. Forty-five subjects per treatment arm were required to yield at least $80 \%$ power at an $\alpha$ level of 0.05 to conclude that the ORR of PICN was within $14 \%$ of the ORR of $n a b$-paclitaxel (1-sided). Taking into account a dropout rate of approximately $25 \%$, the projected sample size required was 180 (60 patients per study arm). These assumptions were based on the reconciled target lesion response rate in the randomized Phase III study comparing efficacy of nab-paclitaxel to Taxol in patients with metastatic breast cancer which led to regulatory approval of nab-paclitaxel (Study CA012-0). The reconciled target lesion response rate observed in the Phase III nab-paclitaxel study was $21.5 \%$ [8].

All statistical analyses were performed using SAS version 9.2 software (SAS Institute Inc., Cary, NC). Comparison of baseline demographic and clinical variables was performed using a Chi-square test for categorical variables, Mann-Whitney $U$ test for ordinal variables, and student $t$ test for interval variables. All tests were 2-tailed, and the 


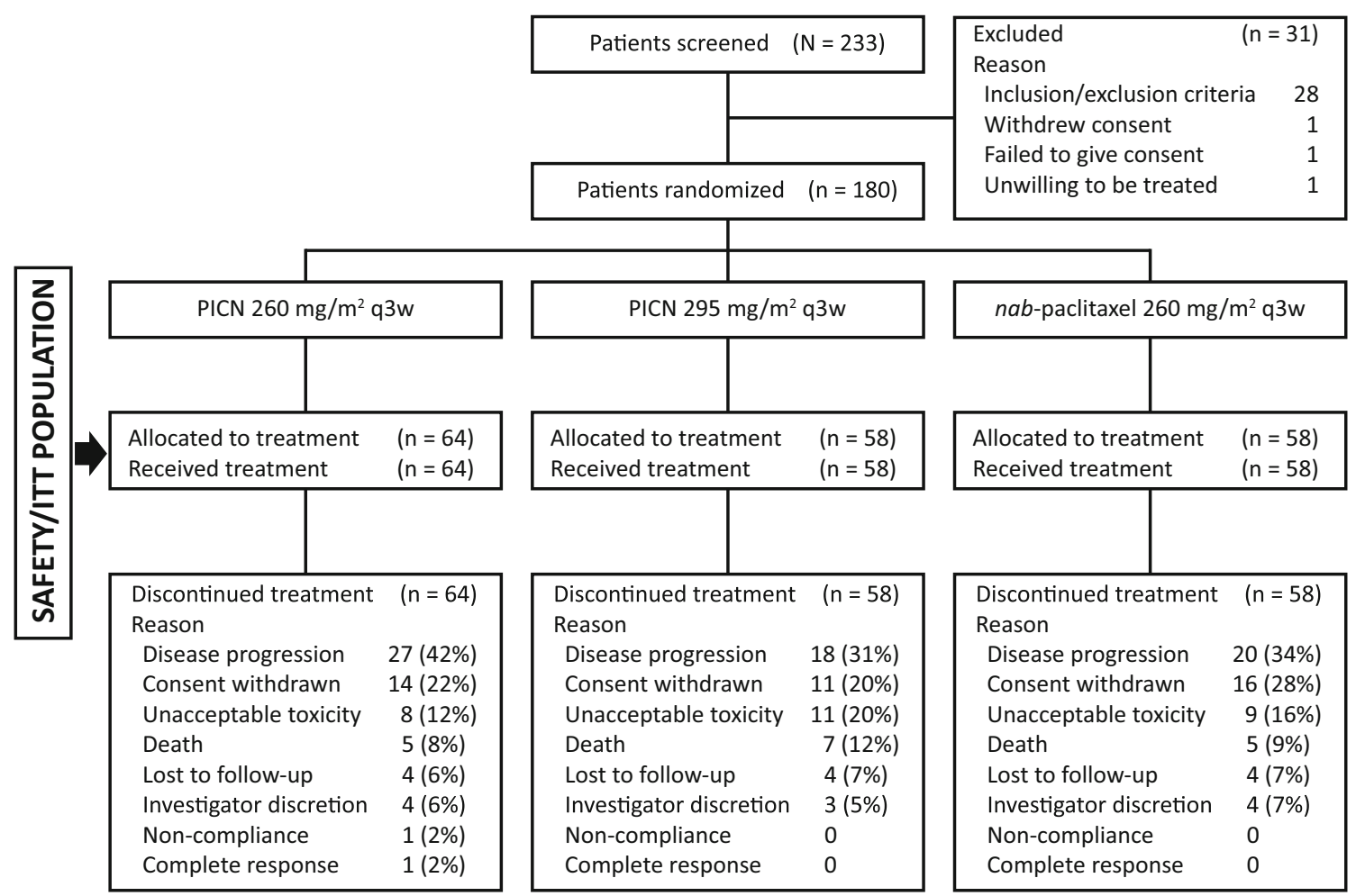

Fig. 1 CONSORT diagram of the participants. ITT intent to treat, PICN paclitaxel injection concentrate for nanodispersion; $q 3 w$ every 3 weeks

level of significance was set at .05. Compliance was measured as the percentage of scheduled doses administered and was compared between groups using student $t$ test. ORRs were compared using the Chi-square test. Progression-free survival was measured using KaplanMeier analysis and compared using the log-rank test.

\section{Results}

\section{Patient characteristics}

From July 2010 to April 2013, 233 patients were screened; 180 were randomized to treatment and comprised the intent to treat (ITT)/safety population (Fig. 1). There were no statistically significant differences across the treatment arms with respect to baseline demographic and clinical characteristics (Table 1). Patient disposition and reasons for treatment discontinuations are detailed in the CONSORT diagram (Fig. 1). The proportion of patients who discontinued treatment for specific reasons was similar across the treatment arms, including the proportion who discontinued because of disease progression $(n=13$ [27 \%] in the PICN 260-mg/m $\mathrm{m}^{2}$ arm; $n=18$ [31\%] in the PICN $295-\mathrm{mg} / \mathrm{m}^{2}$ arm; $n=20$ [34 \%] in the $n a b$-paclitaxel $260-\mathrm{mg} / \mathrm{m}^{2}$ arm).

The mean ( \pm standard deviation $[\mathrm{SD}])$ cumulative doses administered during the study were $2026 \pm 1391 \mathrm{mg} / \mathrm{m}^{2}$ in the PICN $260-\mathrm{mg} / \mathrm{m}^{2}$ arm, $2260 \pm 1823 \mathrm{mg} / \mathrm{m}^{2}$ in the PICN $295-\mathrm{mg} / \mathrm{m}^{2}$ arm, and $2290 \pm 1293 \mathrm{mg} / \mathrm{m}^{2}$ in the nab-paclitaxel $260-\mathrm{mg} / \mathrm{m}^{2}$ arm. Mean dose intensities were $155 \pm 88 \mathrm{mg} / \mathrm{m}^{2}, 186 \pm 126 \mathrm{mg} / \mathrm{m}^{2}$, and $137 \pm 61 \mathrm{mg} / \mathrm{m}^{2}$, respectively. The mean number of cycles administered per patient was $5.2 \pm 3.5$ in the $\mathrm{PICN} 260-\mathrm{mg} / \mathrm{m}^{2}$ arm, $5.07 \pm 3.7$ in the PICN $295-\mathrm{mg} / \mathrm{m}^{2}$ arm, and $5.9 \pm 3.5$ in the $n a b$-paclitaxel $260-\mathrm{mg} / \mathrm{m}^{2}$ arm. Treatment was administered at the specified dosage without dose reduction in $92 \%$ $(n=59), 86 \%(n=50)$, and $88 \%(n=51)$ of patients in the PICN $260-\mathrm{mg} / \mathrm{m}^{2}$, PICN $295-\mathrm{mg} / \mathrm{m}^{2}$, and $n a b$-paclitaxel $260-\mathrm{mg} / \mathrm{m}^{2}$ arms, respectively.

\section{Efficacy}

The independent radiologist-assessed ORRs in the evaluable population were 35,49 , and $43 \%$ in the PICN $260-\mathrm{mg} / \mathrm{m}^{2}$, PICN $295-\mathrm{mg} / \mathrm{m}^{2}$, and $n a b$-paclitaxel $260-\mathrm{mg} / \mathrm{m}^{2}$ arms, respectively, which revealed no significant difference when comparing the PICN $260-\mathrm{mg} / \mathrm{m}^{2}$ arm $(p=0.7613)$ or the PICN $295-\mathrm{mg} / \mathrm{m}^{2}$ arm $(p=0.6233)$ with the nab-paclitaxel $260-\mathrm{mg} / \mathrm{m}^{2}$ arm (Table 2).

Median PFS was 23 weeks [95\% confidence interval (CI) 21-21 weeks], 35 weeks (95\% CI 27 to not reached weeks), and 34 weeks (95\% CI 25 to not reached weeks) in the PICN $260-\mathrm{mg} / \mathrm{m}^{2}$, PICN $295-\mathrm{mg} / \mathrm{m}^{2}$, and $n a b$-paclitaxel 260-mg/m $\mathrm{m}^{2}$ arms, respectively (Fig. 2). There was 
Table 1 Patient baseline demographic and clinical characteristics

\begin{tabular}{|c|c|c|c|c|c|c|}
\hline \multirow[t]{2}{*}{ Characteristic $^{\mathrm{a}}$} & \multicolumn{2}{|c|}{ PICN $260 \mathrm{mg} / \mathrm{m}^{2}(n=64)$} & \multicolumn{2}{|c|}{ PICN $295 \mathrm{mg} / \mathrm{m}^{2}(n=58)$} & \multicolumn{2}{|c|}{$n a b$-paclitaxel $260 \mathrm{mg} / \mathrm{m}^{2}(n=58)$} \\
\hline & \multicolumn{2}{|c|}{ No. of patients (\%) } & \multicolumn{2}{|c|}{ No. of patients (\%) } & \multicolumn{2}{|c|}{ No. of patients (\%) } \\
\hline \multicolumn{7}{|l|}{ Age (years) } \\
\hline Median & \multicolumn{2}{|l|}{50} & \multicolumn{2}{|l|}{49} & \multicolumn{2}{|l|}{51} \\
\hline Range & \multicolumn{2}{|l|}{$32-68$} & \multicolumn{2}{|c|}{$27-70$} & \multicolumn{2}{|c|}{$35-69$} \\
\hline \multicolumn{7}{|l|}{ Race } \\
\hline Asian & 64 & 100 & 58 & 100 & 58 & 100 \\
\hline \multicolumn{7}{|l|}{ Weight (kg) } \\
\hline Median & \multicolumn{2}{|l|}{54} & \multicolumn{2}{|l|}{55} & \multicolumn{2}{|l|}{56} \\
\hline Range & \multicolumn{2}{|l|}{$33-84$} & \multicolumn{2}{|c|}{$33-110$} & \multicolumn{2}{|c|}{$34-90$} \\
\hline \multicolumn{7}{|l|}{ Height $(\mathrm{cm})$} \\
\hline Median & \multicolumn{2}{|l|}{151} & \multicolumn{2}{|l|}{152} & \multicolumn{2}{|l|}{153} \\
\hline Range & \multicolumn{2}{|l|}{$138-164$} & $140-$ & & $136-$ & \\
\hline Menopausal status & & & & & & \\
\hline Postmenopausal & 50 & 78 & 44 & 76 & 45 & 78 \\
\hline Premenopausal & 14 & 22 & 14 & 24 & 13 & 22 \\
\hline ECOG PS ${ }^{\mathrm{a}}$ & & & & & & \\
\hline 0 & 28 & 44 & 26 & 45 & 31 & 53 \\
\hline 1 & 34 & 53 & 31 & 53 & 25 & 43 \\
\hline 2 & 2 & 3 & 1 & 2 & 2 & 3 \\
\hline Prior breast cancer & apy & & & & & \\
\hline Chemotherapy & 63 & 98 & 46 & 79 & 55 & 95 \\
\hline Radiotherapy & 18 & 28 & 19 & 33 & 11 & 19 \\
\hline Surgery & 51 & 80 & 46 & 79 & 42 & 72 \\
\hline No. of prior chem & apy regime & & & & & \\
\hline 0 & 5 & 8 & 14 & 24 & 8 & 14 \\
\hline 1 & 43 & 67 & 27 & 47 & 35 & 60 \\
\hline 2 & 7 & 11 & 10 & 17 & 8 & 14 \\
\hline$\geq 3$ & 9 & 14 & 7 & 12 & 7 & 12 \\
\hline No. of lesions ${ }^{\mathrm{b}}$ & & & & & & \\
\hline Median & 5 & & 5 & & 4.5 & \\
\hline Range & $2-9$ & & $2-12$ & & $2-13$ & \\
\hline Dominant metastat & & & & & & \\
\hline Liver & 19 & 30 & 16 & 28 & 21 & 36 \\
\hline Lung & 19 & 30 & 14 & 24 & 18 & 31 \\
\hline Bone & 9 & 14 & 7 & 12 & 12 & 21 \\
\hline CNS & 0 & 0 & 0 & 0 & 1 & 2 \\
\hline Other & 39 & 61 & 38 & 66 & 34 & 59 \\
\hline
\end{tabular}

ECOG Eastern Cooperative Oncology Group, CNS central nervous system, PICN paclitaxel injection concentrate for nanodispersion, $P S$ performance status

${ }^{a}$ Descriptive statistics performed to provide evidence that the groups were balanced with no statistically significant between groups $(p>0.1)$

b Percentages may not total 100 because of rounding

${ }^{c}$ Includes target and nontarget lesions

no significant difference in PFS between the PICN $260-\mathrm{mg} / \mathrm{m}^{2} \quad(p=0.1085) \quad$ or $\quad \mathrm{PICN} \quad 295-\mathrm{mg} / \mathrm{m}^{2}$ $(p=0.9430)$ arms compared with the nab-paclitaxel $260-\mathrm{mg} / \mathrm{m}^{2}$ arm.

\section{Safety}

The most common AEs of any grade and grade 3/4 per patient irrespective of treatment relationship across all 
Table 2 Independent radiologist-assessed response rates (evaluable population)

\begin{tabular}{|c|c|c|c|c|c|c|c|c|c|}
\hline & \multicolumn{3}{|c|}{ PICN $260 \mathrm{mg} / \mathrm{m}^{2}(n=48)$} & \multicolumn{3}{|c|}{$\mathrm{PICN} 295 \mathrm{mg} / \mathrm{m}^{2}(n=41)$} & \multicolumn{3}{|c|}{$n a b$-paclitaxel $260 \mathrm{mg} / \mathrm{m}^{2}(n=47)$} \\
\hline & No. of patients & $(\%)$ & $95 \%$ CI (\%) & No. of patients & $(\%)$ & $95 \%$ CI (\%) & No. of patients & $(\%)^{\mathrm{a}}$ & $95 \% \mathrm{CI}(\%)$ \\
\hline $\mathrm{ORR}(\mathrm{CR}+\mathrm{PR})$ & 17 & $35^{\mathrm{b}}$ & $22.2-50.5$ & 20 & $49^{c}$ & $32.9-64.9$ & 20 & 43 & $36.6-63.4$ \\
\hline SD & 18 & 38 & & 14 & 34 & & 15 & 32 & \\
\hline PD & 13 & 27 & & 7 & 17 & & 12 & 26 & \\
\hline
\end{tabular}

$C I$ confidence interval, $C R$ complete response, $O R R$ overall response rate, $P I C N$ paclitaxel injection concentrate for nanodispersion, $P D$ progressive disease, $P R$ partial response, $S D$ stable disease

${ }^{\text {a }}$ Percentages do not total 100 because of rounding

${ }^{\mathrm{b}} p=0.7613$ versus $n a b$-paclitaxel

${ }^{c} p=0.6233$ versus $n a b$-paclitaxel
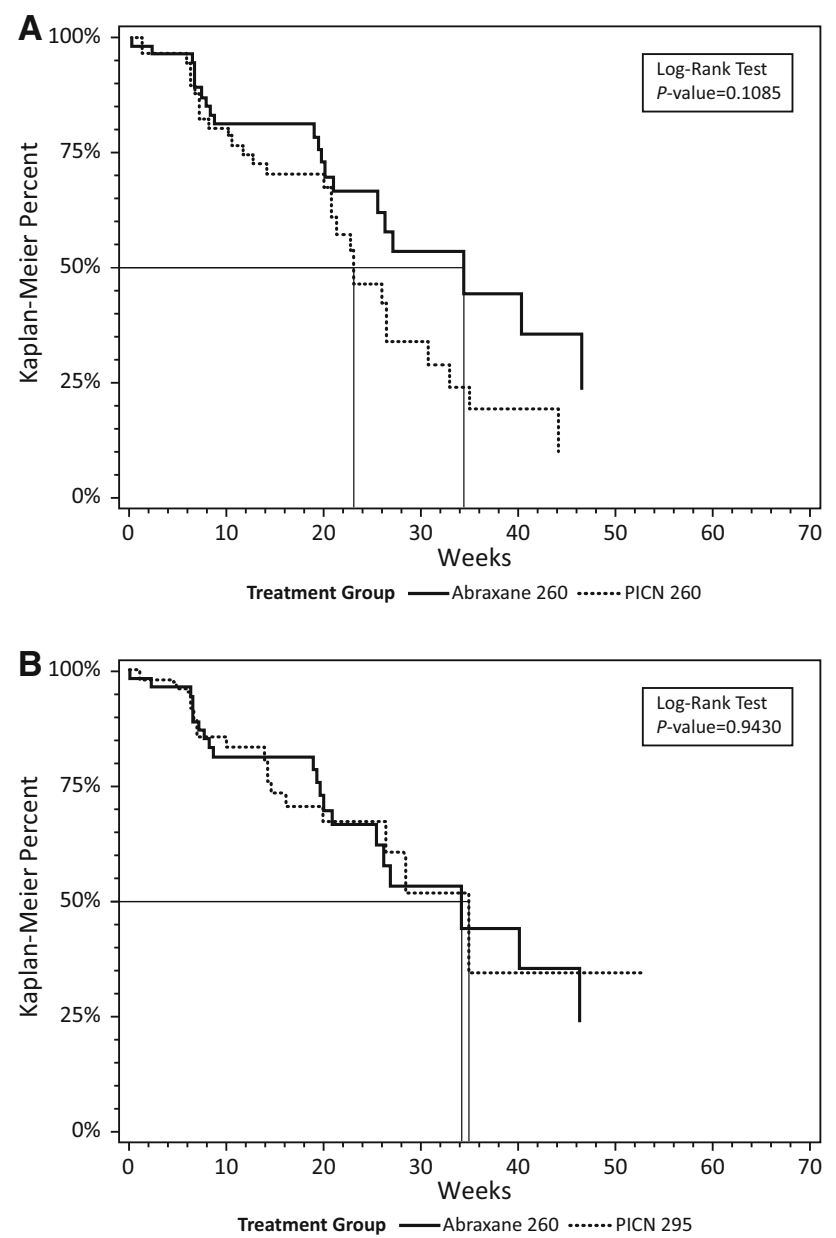

Fig. 2 Kaplan-Meier plots of progression-free survival comparing a PICN $260 \mathrm{mg} / \mathrm{m}^{2}$ and $n a b$-paclitaxel $260 \mathrm{mg} / \mathrm{m}^{2}$ and b PICN $295 \mathrm{mg} / \mathrm{m}^{2}$ and $n a b$-paclitaxel $260 \mathrm{mg} / \mathrm{m}^{2}$. PICN paclitaxel injection concentrate for nanodispersion

cycles are summarized in Table 3. Adverse events of any grade were generally reported in similar proportions of patients across the treatment arms. Grade 3/4 AEs were reported in a lower proportion of patients in the PICN $260-\mathrm{mg} / \mathrm{m}^{2}$ arm compared with those in the PICN $295-\mathrm{mg} / \mathrm{m}^{2}$ and $n a b$-paclitaxel $260-\mathrm{mg} / \mathrm{m}^{2}$ arms, with a similar prevalence in the latter 2 arms: neutropenia (12 vs. 24 vs. $21 \%$ ); peripheral neuropathy ( 8 vs. 21 vs. $17 \%$ ); and leukopenia (9 vs. 14 vs. $16 \%)$, respectively.

There were 46, 53, and 28 serious AEs irrespective of treatment relationship reported for all cycles in the PICN 260-mg/ $\mathrm{m}^{2}$, PICN 295-mg/m $/ \mathrm{m}^{2}$, and $n a b$-paclitaxel 260-mg/ $\mathrm{m}^{2}$ arms, respectively. The most frequently ( $\geq 5 \%$ in any arm) reported serious AEs were diarrhea (13 vs. 2 vs. $7 \%$ ); infection (9 vs. 6 vs. $11 \%$ ); mucosal inflammation (9 vs. 8 vs. $7 \%$ ); neutropenia (7 vs. 9 vs. $7 \%$ ); pyrexia (9 vs. 2 vs. $4 \%$ ); thrombocytopenia (0 vs. 9 vs. $4 \%$ ); death ( 8 vs. 12 vs. $9 \%$ ); febrile neutropenia ( 2 vs. 6 vs. $7 \%$ ); cardiac arrest ( 2 vs. 4 vs. $7 \%$ ); nausea ( 2 vs. 2 vs. $7 \%$ ); and leukopenia ( 2 vs. 6 vs. $4 \%$ ).

Unacceptable toxicity resulting in treatment discontinuation occurred in $8(12 \%), 11(20 \%)$, and $9(16 \%)$ patients in the PICN $260-\mathrm{mg} / \mathrm{m}^{2}$, PICN $295-\mathrm{mg} / \mathrm{m}^{2}$, and $n a b$-paclitaxel $260-\mathrm{mg} / \mathrm{m}^{2}$ arms, respectively, and death occurred in $5(8 \%), 7(12 \%)$, and $5(9 \%)$ patients, respectively.

\section{Discussion}

Careful consideration was given to selecting the comparative dosages in this phase II/III trial. The PICN 295-mg/ $\mathrm{m}^{2}$ dosage was the maximum tolerated dose in a previously performed phase I study in women with MBC. Since the PICN $295-\mathrm{mg} / \mathrm{m}^{2}$ dosage was obtained from the phase I study with a limited sample size, additionally $260 \mathrm{mg} / \mathrm{m}^{2}$ was selected as the comparator against the approved and indicated dosage of $n a b$-paclitaxel $260 \mathrm{mg} / \mathrm{m}^{2}$ for MBC because it was the next lower dosage step [13].

There were no statistically significant differences between the treatment arms with respect to independent 
Table 3 Most common adverse events over all cycles

\begin{tabular}{|c|c|c|c|c|c|c|}
\hline & \multicolumn{2}{|c|}{ PICN $260 \mathrm{mg} / \mathrm{m}^{2}(n=64)$} & \multicolumn{2}{|c|}{ PICN $295 \mathrm{mg} / \mathrm{m}^{2}(n=58)$} & \multicolumn{2}{|c|}{$n a b$-paclitaxel $260 \mathrm{mg} / \mathrm{m}^{2}(n=58)$} \\
\hline & No. of patients & $(\%)$ & No. of patients & $(\%)$ & No. of patients & $(\%)$ \\
\hline \multicolumn{7}{|c|}{ Any grade $\mathrm{AE}$ occurring in $\geq 20 \%$ of patients in any arm, by preferred term ${ }^{\mathrm{a}}$} \\
\hline Pain & 36 & 56 & 34 & 59 & 39 & 67 \\
\hline Peripheral neuropathy & 37 & 58 & 37 & 64 & 35 & 60 \\
\hline Alopecia & 24 & 37 & 21 & 36 & 30 & 52 \\
\hline Mucosal inflammation & 26 & 41 & 25 & 43 & 23 & 40 \\
\hline Asthenia & 24 & 37 & 24 & 42 & 21 & 36 \\
\hline Nausea & 14 & 22 & 16 & 28 & 21 & 36 \\
\hline Pyrexia & 19 & 30 & 20 & 34 & 20 & 34 \\
\hline Neutropenia & 21 & 33 & 24 & 41 & 19 & 33 \\
\hline Leukopenia & 19 & 30 & 18 & 31 & 16 & 28 \\
\hline Cough & 14 & 22 & 15 & 26 & 13 & 22 \\
\hline Infection & 13 & 20 & 11 & 19 & 15 & 26 \\
\hline Vomiting & 16 & 25 & 8 & 14 & 9 & 16 \\
\hline Diarrhea & 16 & 25 & 9 & 16 & 8 & 14 \\
\hline Anemia & 9 & 14 & 14 & 24 & 9 & 16 \\
\hline Anorexia & 10 & 16 & 13 & 22 & 13 & 22 \\
\hline Pruritus & 13 & 20 & 12 & 21 & 9 & 16 \\
\hline \multicolumn{7}{|c|}{ Grade $3 / 4 \mathrm{AE}$ occurring in $\geq 5 \%$ of patients in any arm, by preferred term ${ }^{\mathrm{a}}$} \\
\hline Neutropenia & 8 & 12 & 14 & 24 & 12 & 21 \\
\hline Peripheral neuropathy & 5 & 8 & 12 & 21 & 10 & 17 \\
\hline Leukopenia & 6 & 9 & 8 & 14 & 9 & 16 \\
\hline Anemia & 1 & 2 & 5 & 9 & 2 & 3 \\
\hline Febrile neutropenia & 1 & 2 & 4 & 7 & 2 & 3 \\
\hline Pain & 2 & 3 & 3 & 5 & 4 & 7 \\
\hline Asthenia & 3 & 5 & 3 & 5 & 4 & 7 \\
\hline Infection & 2 & 3 & 3 & 5 & 3 & 5 \\
\hline
\end{tabular}

$A E$ adverse event, $P I C N$ paclitaxel injection concentrate for nanodispersion

${ }^{a}$ Coded by MedDRA version 14.0

radiologist-assessed ORR in the evaluable population (Table 2). The median PFS was somewhat lower in the PICN $260-\mathrm{mg} / \mathrm{m}^{2}$ arm, after 23 weeks, in comparison to that which was reported for $n a b$-paclitaxel $260 \mathrm{mg} / \mathrm{m}^{2}$ at 34 weeks. It should be noted, however, that this difference was statistically insignificant, and therefore may not be interpreted to have a clinical impact. The median PFS in the PICN $295-\mathrm{mg} / \mathrm{m}^{2}$ arm at 35 weeks was remarkably similar to the PFS observed in the $n a b$-paclitaxel $260-\mathrm{mg} / \mathrm{m}^{2}$ arm at 34 weeks. There was no statistically significant difference between treatment arms. The proportion of patients who discontinued treatment because of disease progression was similar across the study arms, the PICN $260-\mathrm{mg} / \mathrm{m}^{2}$ arm $(n=13 \quad[27 \%])$, the $n a b$-paclitaxel $260-\mathrm{mg} / \mathrm{m}^{2}$ arm $(n=20[34 \%])$, and the PICN $295-\mathrm{mg} / \mathrm{m}^{2}$ arm $(n=18$ [31\%]).

The safety profiles when comparing PICN $295 \mathrm{mg} / \mathrm{m}^{2}$ with $n a b$-paclitaxel $260 \mathrm{mg} / \mathrm{m}^{2}$ were similar, whereas the
PICN 260-mg/ $\mathrm{m}^{2}$ dosage appeared to be somewhat better tolerated than the $n a b$-paclitaxel $260-\mathrm{mg} / \mathrm{m}^{2}$ and PICN $295-\mathrm{mg} / \mathrm{m}^{2}$ dosages. For example, the incidence of each of the most frequent grade 3/4 AEs (neutropenia, peripheral neuropathy, and leukopenia) was lowest in the PICN $260-\mathrm{mg} / \mathrm{m}^{2}$ arm, and similar between PICN $295 \mathrm{mg} / \mathrm{m}^{2}$ and nab-paclitaxel $260 \mathrm{mg} / \mathrm{m}^{2}$ (Table 3). Historically, chemotherapy-induced neutropenia is the most common toxicity associated with the administration of anticancer agents $[20,21]$. In fact, the risk of developing neutropenia is $>20 \%$ for those patients with MBC exposed to dosedense anthracycline/taxane- and docetaxel-based regimens [22]. Head-to-head studies of patients with MBC randomized to polyoxyethylated castor oil-paclitaxel $\left(175 \mathrm{mg} / \mathrm{m}^{2}\right.$ every 3 weeks), docetaxel $\left(100 \mathrm{mg} / \mathrm{m}^{2}\right.$ every 3 weeks $)$, and $n a b$-paclitaxel $\left(260 \mathrm{mg} / \mathrm{m}^{2}\right.$ to $300 \mathrm{mg} / \mathrm{m}^{2}$ every 3 weeks) have been performed. They demonstrated rates of grade $3 / 4$ neutropenia ranging from 46 to $54.5 \%$ for 
polyoxyethylated castor oil-paclitaxel $(N=444), 92$ to $93.3 \%$ for docetaxel $(N=296)$, and $31-43 \%$ for $n a b$ paclitaxel $(N=302)$ [23]. These rates of grade $3 / 4$ neutropenia are in sharp contrast to those observed in the present study, where rates were reported to be $33 \%$ for patients in the PICN $260-\mathrm{mg} / \mathrm{m}^{2}$ arm, and 41 and $33 \%$ for those patients in the PICN $295-\mathrm{mg} / \mathrm{m}^{2}$ and $n a b$-paclitaxel $260-\mathrm{mg} / \mathrm{m}^{2}$ arms, respectively. The safety results in the current study were also reflected in the rates of discontinuation for unacceptable toxicity in the respective arms.

In addition, the initial hypothesis, of a decreased incidence of hypersensitivity reactions due to the presence of polyoxyethylated castor oil and albumin in the comparator, was substantiated by the highly limited number of hypersensitivity reactions reported with PICN $3.13 \%$ for PICN $260 \mathrm{mg} / \mathrm{m}^{2}, 0.0 \%$ for PICN $295 \mathrm{mg} / \mathrm{m}^{2}$, and $1.72 \%$ for $n a b$-paclitaxel). Incidence of hypersensitivity reactions reported for polyoxyethylated castor oil-containing paclitaxel formulations is between 25 and $30 \%$ [3]. Reported grade 3/4 neuropathies were also limited with both dosages of PICN, and comparable to those reported with the comparator, nab-paclitaxel. The clinical observations of this study also indicate that despite chemical dissimilarities and differences between the nanotechnology platforms used for the studied taxane formulations, PICN has similar efficacy and safety to nabpaclitaxel as demonstrated in this trial in patients with metastatic breast cancer. Similar to nab-paclitaxel, PICN administration did not require corticosteroid pretreatment and was well tolerated.

In conclusion, PICN $295 \mathrm{mg} / \mathrm{m}^{2}$ and PICN $260 \mathrm{mg} / \mathrm{m}^{2}$ every 3 weeks was as effective and showed similar tolerability compared with $n a b$-paclitaxel $260 \mathrm{mg} / \mathrm{m}^{2}$ every 3 weeks in the treatment of women with MBC. The current study showed that additive-free PICN, when used in women with refractory $\mathrm{MBC}$, is as effective and well tolerated as additive-containing formulations of paclitaxel (i.e., nab-paclitaxel), and may have potential advantage of decreased use of pretreatment corticosteroids.

Acknowledgments Editorial assistance was provided by James A. Shiffer, RPh, Write On Time Medical Communications, LLC, and was supported by Sun Pharma Advanced Research Co. Ltd.

Funding This study was funded by Sun Pharma Advanced Research Co. Ltd.

\section{Compliance with ethical standards}

Disclosures Drs. Ajay Khopade, Shravanti Bhowmik, and Geetanjali Chimote are employed by Sun Pharma Advanced Research Co. Ltd and associated with this study. Dr. Khopade owns stock in Sun Pharma Advanced Research Co. Ltd. Authors Minish M. Jain, Shekhar G. Patil, Anand B. Pathak, Chetan D. Deshmukh, Niraj Bhatt, K. Govind Babu, Chiramana Haritha, Shailesh A. Bondarde, Raghunadharao Digumarti, Jyoti Bajpai, Ravi Kumar, Smita U. Gupte,
Ashish V. Bakshi, Gouri Sankar Bhattacharyya, Poonam Patil, Sundaram Subramanian, Ashok K. Vaid, Chirag J. Desai, and Poonamalle P. Bapsy received research funding from Sun Pharma Advanced Research Co. Ltd. Poonamalle P. Bapsy is employed by Sun Pharma Advanced Research Co. Ltd.

Open Access This article is distributed under the terms of the Creative Commons Attribution-NonCommercial 4.0 International License (http://creativecommons.org/licenses/by-nc/4.0/), which permits any noncommercial use, distribution, and reproduction in any medium, provided you give appropriate credit to the original author(s) and the source, provide a link to the Creative Commons license, and indicate if changes were made.

\section{References}

1. Gradishar WJ (2012) Taxanes for the treatment of metastatic breast cancer. Breast Cancer (Auckl) 6:159-171

2. Taxol ${ }^{\circledR}$ (paclitaxel) Injection [prescribing information]. Princeton, NJ: Bristol-Myers Squibb Co.; 2011

3. Rowinsky EK, Donehower RC (1995) Paclitaxel (taxol). N Engl J Med 332:1004-1014

4. Weiss RB, Donehower RC, Wiernik PH et al (1990) Hypersensitivity reactions from Taxol. J Clin Oncol 8:1263-1268

5. Kloover JS, den Bakker MA, Gelderblom H, van Meerbeeck JP (2004) Fatal outcome of a hypersensitivity reaction to paclitaxel: a critical review of premedication regimens. $\mathrm{Br} \mathrm{J}$ Cancer 90:304-305

6. Waugh WN, Trissel LA, Stella VJ (1991) Stability, compatibility, and plasticizer extraction of taxol (NSC-125973) injection diluted in infusion solutions and stored in various containers. Am J Hosp Pharm 48:1520-1524

7. Abraxane ${ }^{\circledR}$ for Injectable Suspension (paclitaxel protein-bound particles for injectable suspension) (albumin bound) [prescribing information]. Summit, NJ: Abraxis BioScience, LLC; Oct 2013

8. NDA-21660, Abraxane, Medical Review (S), Centre for Drug Evaluation and Research; 2005

9. Ibrahim NK, Desai N, Legha S et al (2002) Phase I and pharmacokinetic study of ABI-007, a Cremophor-free, protein-stabilized, nanoparticle formulation of paclitaxel. Clin Cancer Res 8:1038-1044

10. Gradishar WJ, Krasnojon D, Cheporov S et al (2009) Significantly longer progression-free survival with nab-paclitaxel compared with docetaxel as first-line therapy for metastatic breast cancer. J Clin Oncol 27:3611-3619

11. Ibrahim NK, Samuels B, Page R et al (2005) Multicenter phase II trial of ABI-007, an albumin-bound paclitaxel, in women with metastatic breast cancer. J Clin Oncol 23:6019-6026

12. Gradishar WJ, Tjulandin S, Davidson N et al (2005) Phase III trial of nanoparticle albumin-bound paclitaxel compared with polyethylated castor oil-based paclitaxel in women with breast cancer. J Clin Oncol 23:7794-7803

13. Jain MM, Deshmukh CD, Bhatt NN, et al. (2011) Phase I, PK, dose-finding, active controlled study of paclitaxel injection concentrate for nanodispersion (PICN) in subjects with metastatic breast cancer. J Clin Oncol, 29: (suppl; abstr e11585)

14. Lombardi D, Crivellari D et al (2004) Long term, Weekly one hour infusion of paclitaxel in patients with metastatic breast cancer: a Phase II monoinstitutional study. Tumori 19:285-288

15. Eniu A, Palmieri FM et al (2005) Weekly administration of docetaxel and paclitaxel in metastatic or advanced breast cancer. Oncologist 10:665-685

16. Blum JL, Savin MA et al (2007) Phase II study of weekly albuminbound paclitaxel for patients with metastatic breast cancer heavily pretreated with taxanes. Clin Breast Cancer 7:850-856 
17. Rugo HS, Barry WT, et al. (2012) CALGB 40502/NCCTG N063H: randomized phase III trial of weekly paclitaxel (P) compared to weekly nanoparticle albumin bound nab-paclitaxel (NP) or ixabepilone (Ix) with or without bevacizsumab (B) as first-line therapy for locally recurrent or metastatic breast cancer (MBC). J Clin Oncol, 30 (suppl; abstr CRA1002)

18. Jain MM, Patil S, et al. (2014) The efficacy and safety of paclitaxel injection concentrate for nano-dispersion (PICN) at two different doses versus paclitaxel albumin-stabilized nanoparticle formulation in subjects with metastatic breast cancer (MBC). J Clin Oncol, 32: (suppl; abstr 1069)

19. Ma WW, Diamond JR (2014) A phase I and pharmacokinetic study of a weekly dosing schedule of paclitaxel injection concentrate for nano-dispersion (PICN) in patients with advanced solid tumors. J Clin Oncol, 32:(suppl; abstr 2566)
20. Crawford J, Wolff DA, Culakova E et al (2004) First cycle risk of severe and febrile neutropenia in cancer patients receiving systemic chemotherapy: results from a prospective nationwide study. Blood 104:607a-608a Abstract 2210

21. Culakova E, Thota R, Poniewierski MS et al (2014) Patterns of chemotherapy-associated toxicity and supportive care in US oncology practice: a nationwide prospective cohort study. Cancer Med 3:434-444

22. National Comprehensive Cancer Network. NCCN guidelines. Myeloid growth factors. www.ncen.org/professionals/physician_ gls/pdf/myeloid_growth.pdf. Accessed 6 Oct 2015

23. Gradishar WJ (2012) Taxanes for the treatment of metastatic breast cancer. Breast Cancer (Auckl) 6:159-171 